\title{
NONLINEAR STRUCTURAL IRESPONSE OF LAMINATED COMPOSITE PANELS SUBJECTED TO BLAST LOADINGS
}

\author{
Halit S. TÜRKMEN, Zahit MECITOĞLU and Oğuz BORAT \\ Istanbul Technical University, Aeronautics and Astronautics Faculty \\ Maslak, Istanbul 80626 Turkey
}

\begin{abstract}
This paper presents a theoretical analysis and correlation with numerical results of the displacement time histories of laminated composite panels exposed to normal blast shock waves. Nonlinear dynamic equations of the cylindrically curved laminated panels are derived by the use of the Lagrange equations in the frame of Love's theory of thin shells. The governing equations of the laminated curved panel are solved by Runge-Kutta method. In addition, ANSYS finite element software is used to obtain displacement time history numerically. The effect of loading conditions and geometrical properties is examined on the dynamic behavior.
\end{abstract}

\section{INTRODUCTION}

Advanced composites are being used in many applications ranging from aircraft and submarines to pressure vessels and automotive parts. The air blast load which is produced after detonation within a tube consists of several pulses of very complex waveform. The waveform is complex because of the complication of the shock waves. Blast is a type of extraordinary dynamic load to which structures may be subjected in addition to normal loads, and may cause severe damage to the structural mernbers.

The assesment of the effects of the explosives on structural systems was apparently not studied systematically until World War I. The early published work was that of Hopkinson [1] in which he outlined his theory for using scale models with the statement: "If two structural systems, identically similar except in size, be subjected to blast loading from two explosive charges whose weights are in proportion to the cube of the ratio of the linear dimensions of the two structures, then the behavior of the two structural systems will be identically similar with the distorsions scaling as the ratio of the linear dimensions."

Studies concerning a blast loading on a panel were carried out by Houlston et al. [2], Houlston and DesRochers [3], Gupta et al. [4], Redekop and Azar [5]. Recently, Türkmen and Mecitoglu [6] carried out a numerical study on the dynamic behavior of laminated composite plates subjected to shock loading. Librescu and Nosier [7] took into account of the shear deformation effect in the theoretical analysis of the symmetrically laminated rectangular composite flat panels exposed to blast loadings. Reddy [8] investigated the forced motions of laminated composite plates using a finite element that accounts for the transverse shear strains, rotary inertia and large rotations. Beshara [9] investigated the prediction of dynamic effects of unconfined explosions needed for the structural analysis of blast-loaded aboveground structures. 
In this study, the nonlinear geometric analysis of cylindrically curved laminated panels subjected to blast loadings is investigated. The Love's thin shell theory is used in the nonlinear range. It is assumed that the shell is thin, transverse shear strains are neglected and large deflections are included. The equation of motion is obtained by using Lagrange equation. The forth order Runge-Kutta method is used to obtain solutions. In addition ANSYS finite element software is used to obtain displacement time history in the linear range.

\section{NONLINEAR DYNAMIC RESPONSE ANALYSIS}

The laminated circular cylindrical shell panel is depicted in Fig. 1 where $x, \theta$ and $z$ are cylindrical coordinates; $u, v$ and $w$ are displacements at $x, \theta$ and $z$ directions respectively; $l$ and $s_{0}$ are dimensions of circular cylindrical shell panel, $r$ is the radius of curvature.

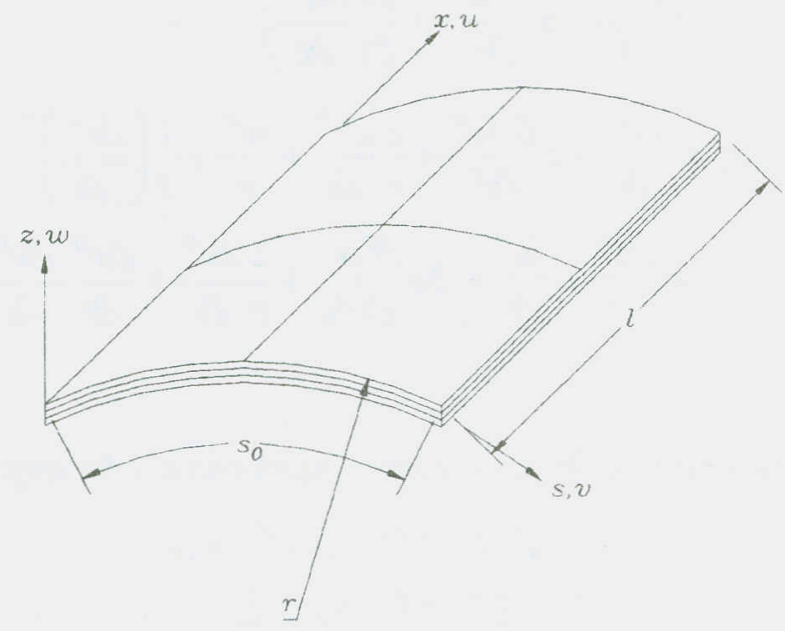

Fig. 1. Laminated shell geometry.

\section{Governing Equations}

The displacement field in the shell can be represented by polinomials or trigonometric series [10]. The first few terms of the series expansion for the displacements $u, v, w$ are derived as [11]

$$
\begin{aligned}
& u=u^{0}+u^{a} \frac{z}{h}+u^{s} \sin \frac{\pi z}{h} \\
& v=v^{0}+v^{a} \frac{z}{h}+v^{s} \sin \frac{\pi z}{h} \\
& w=w^{0}+w^{a} \frac{z}{h}+w^{c} \cos \frac{\pi z}{h}
\end{aligned}
$$

where $u, v$ and $w$ are the displacement components in the directions of axes $x, \theta$ and $z$, respectively; $u^{0}, v^{0}$ and $w^{0}$ are the displacement components of the middle surface of the shell. In classical cylindrical shell theory, the $w^{a}$ term and the trigonometric terms are absent 
and the terms $u^{a} / h$ and $v^{a} / h$ are replaced by $-2 w^{0} / \partial x$ and $-2 w^{0} / r \partial \theta+v^{0} / r$, respectively.

Strain-displacement relationships for the cylindrical shell can be written as

$$
\begin{aligned}
& \varepsilon_{x}=\frac{\partial u}{\partial x}+\frac{I}{2}\left(\frac{\partial w}{\partial x}\right)^{2} \\
& \varepsilon_{\theta}=\frac{1}{r} \frac{\partial}{\partial \theta}+\frac{w}{r}+\frac{1}{2} \frac{1}{r^{2}}\left(\frac{\partial w}{\partial \theta}\right)^{2} \\
& \varepsilon_{x \theta}=\frac{1}{r} \frac{\partial u}{\partial \theta}+\frac{\partial}{\partial x}+\frac{1}{r} \frac{\partial w}{\partial x} \frac{\partial w}{\partial \theta}
\end{aligned}
$$

where $\varepsilon_{x}, \varepsilon_{\theta}, \varepsilon_{x \theta}$ are strains in the shell.

If we substitute Eq. (1) into Eq. (2), the strain-displacement relations become

$$
\begin{aligned}
& \varepsilon_{x}=\frac{\partial u^{0}}{\partial x}-z \frac{\partial^{2} w^{0}}{\partial x^{2}}+\frac{1}{2}\left(\frac{\partial w^{0}}{\partial x}\right)^{2} \\
& \varepsilon_{s}=\frac{\partial^{0}}{\partial s}-z \frac{\partial^{2} w^{0}}{\partial s^{2}}+\frac{z}{r} \frac{\partial^{0}}{\partial s}+\frac{w^{0}}{r}+\frac{1}{2}\left(\frac{\partial w^{0}}{\partial s}\right)^{2} \\
& \varepsilon_{x s}=\frac{\partial u^{0}}{\partial s}+\frac{\partial^{0}}{\partial x}-2 z \frac{\partial^{2} w^{0}}{\partial x \partial}+\frac{z}{r} \frac{\partial^{0}}{\partial x}+\frac{\partial w^{0}}{\partial x} \frac{\partial w^{0}}{\partial s}
\end{aligned}
$$

where $s=r \theta$.

For an anisotropic material, the constitutive equations can be expressed as

$$
\begin{aligned}
& \sigma_{x}=\bar{Q}_{11} \varepsilon_{x}+\bar{Q}_{12} \varepsilon_{\theta}+\bar{Q}_{16} \varepsilon_{x \theta} \\
& \sigma_{\theta}=\bar{Q}_{12} \varepsilon_{x}+\bar{Q}_{22} \varepsilon_{\theta}+\bar{Q}_{26} \varepsilon_{x \theta} \\
& \sigma_{x \theta}=\bar{Q}_{16} \varepsilon_{x}+\bar{Q}_{26} \varepsilon_{\theta}+\bar{Q}_{6 \sigma} \varepsilon_{x \theta}
\end{aligned}
$$

where $\sigma_{x}, \sigma_{\theta}, \sigma_{x \theta}$ are stresses and $\bar{Q}_{i j}$ 's are elastic constants for a laminated composite [12].

In the present work, plane inertias and transverse shear strains are ignored. With this assumption, kinetic and potential energies of the shell are given by

$$
\begin{aligned}
& K=1 / 2 \bar{m} \iint(\partial w / \partial t)^{2} r d x d \theta \\
& U=1 / 2 \iint\left(\sigma_{x} \varepsilon_{x}+\sigma_{\theta} \varepsilon_{\theta}+\sigma_{x \theta} \varepsilon_{x \theta}\right) r d x d \theta
\end{aligned}
$$

respectively, where $\bar{m}$ is the shell mass/unit area. The work done by air blast load is expressed as

$$
W_{e}=p(x, s, t) \iint_{A} w d x d s
$$

Equation of motion is obtained by using the Lagrange equation. Hence, Eqs. (5), (6) and (7) are substituted into the Lagrange equation given by 


$$
\frac{d}{d t}\left(\frac{\partial K}{\dot{q}_{i}}\right)+\frac{\partial U}{\partial q_{i}}=\frac{\partial W_{e}}{\partial q_{i}}
$$

Boundary conditions for clamped panels are

$$
\begin{aligned}
& w^{0}(0, s)=w^{0}(l, s)=w^{0}(x, 0)=w^{0}\left(x, s_{0}\right)=0 \\
& \frac{\partial w^{0}}{\partial x}(0, s)=\frac{\partial w^{0}}{\partial x}(l, s)=\frac{\partial w^{0}}{\partial s}(x, 0)=\frac{\partial w^{0}}{\partial s}\left(x, s_{0}\right)=0
\end{aligned}
$$

\section{Blast Loading}

The shock or blast wave is generated when the atmosphere surrounding the explosion is forcibly pushed back by the hot gases produced from the explosion source. The front of the wave, called the shock front, is like a wall of highly compressed air and has an overpressure much greater than that in the region behind it. This peak overpressure decreases rapidly as the shock is propagated outward. After a short time the pressure behind the front may drop below the ambient pressure, as shown in Fig. 2. During such a negative phase, a partial vacuum is created and air is sucked in. The air blast pressure on an exposed surface is a function of the air blast pressure magnitude, and the orientation, geometry and size of the surface which the shock wave encounters.

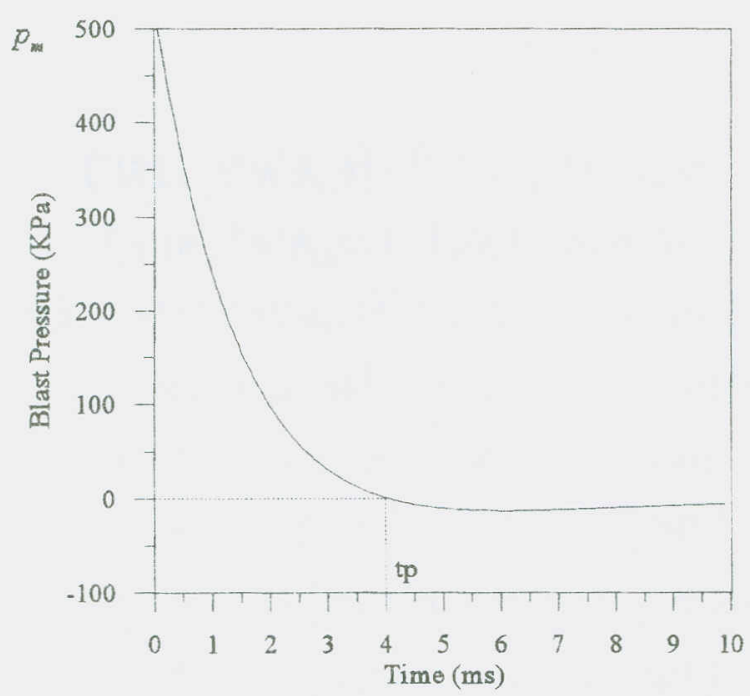

Fig. 2. Variation of blast loading by time.

The variation of total pressure is given by

$$
p(x, s, t)=p_{m}\left(1-\frac{t}{t_{p}}\right) e^{-\alpha \Delta t t_{p}} \sin \left(\frac{\pi x}{l}\right) \sin \left(\frac{\pi s}{s_{0}}\right)
$$

where $p_{m}, t$ and $t_{p}$ are defined in Fig. 2. $\alpha$ is the waveform parameter. Blast loading test results are suitable with the expression in $\mathrm{Eq} .(10)$. 


\section{Solution Method}

The solution is assumed to be multiplication of coordinate and time dependent parts. With this assumption the displacement functions for clamped shell panel are given by the following functions.

$$
\begin{aligned}
& u^{0}=U(t)\left(1-\cos \frac{2 \pi x}{l}\right)\left(1-\cos \frac{2 \pi s}{s_{0}}\right) \\
& v^{0}=V(t)\left(1-\cos \frac{2 \pi x}{l}\right)\left(1-\cos \frac{2 \pi s}{s_{0}}\right) \\
& w^{0}=W(t)\left(1-\cos \frac{2 \pi x}{l}\right)\left(1-\cos \frac{2 \pi s}{s_{0}}\right)
\end{aligned}
$$

After substitution of Eq. (11) into Eqs. (3), (4) and (8), the equation of motion of the circular cylindrical laminated shell panel is obtained as below.

$$
\ddot{W}(t)+S_{1} W(t)+S_{2} W^{2}(t)+S_{3} W^{3}(t)=k p(t)
$$

where

$$
\begin{gathered}
S_{1}=4\left(s_{1}+s_{2}+s_{3}+s_{4}\right) /\left(9 \bar{m} l s_{0}\right) \\
S_{2}=4\left(s_{11}+s_{22}\right) /\left(9 \bar{m} l s_{0}\right) \\
S_{3}=4\left(s_{111}+s_{222}+s_{333}+s_{444}\right) /\left(9 \bar{m} l s_{0}\right) \\
k=\frac{256}{81 \pi^{2} \bar{m}} \\
s_{1}=\left(26 d_{11} h^{3} \pi^{4} s_{0} / 27 l^{3}\right)+\left(k_{11} h^{3} \pi^{4} s_{0} / 27 l^{3}\right) \\
s_{2}=\left(52 d_{12} h^{3} \pi^{4} / 81 l s_{0}\right)+\left(2 k_{12} h^{3} \pi^{4} / 81 l s_{0}\right) \\
s_{3}=\left(26 d_{22} h^{3} l \pi^{4} / 27 s_{0}^{3}\right)+\left(k_{22} h^{3} l \pi^{4} / 27 s_{0}^{3}\right)+\left(3 k_{22}+6 d_{22}\right) h l s_{0} / 4 r^{2} \\
s_{4}=\left(104 d_{66} h^{3} \pi^{4} / 81 l s_{0}\right)+\left(4 k_{66} h^{3} \pi^{4} / 81 l s_{0}\right) \\
s_{11}=\left(10 d_{12} h \pi^{2} s_{0} / 2 l r\right)+\left(5 k_{12} h \pi^{2} s_{0} / 2 l r\right) \\
s_{22}=\left(10 d_{22} h l \pi^{2} / 2 r s_{0}\right)+\left(5 k_{22} h l \pi^{2} / 2 r s_{0}\right) \\
s_{111}=\left(35 d_{11} h \pi^{4} s_{0} / 4 l^{3}\right)+\left(35 k_{11} h \pi^{4} s_{0} / 8 l^{3}\right) \\
s_{222}=\left(25 d_{12} h \pi^{4} / 6 l s_{0}\right)+\left(25 k_{12} h \pi^{4} / 12 l s_{0}\right) \\
s_{333}=\left(35 d_{22} h l \pi^{4} / 4 s_{0}^{3}\right)+\left(35 k_{22} h l \pi^{4} / 8 l^{3}\right) \\
s_{444}=\left(25 d_{66} h \pi^{4} / 3 l s_{0}\right)+\left(25 k_{66} h \pi^{4} / 6 l s_{0}\right)
\end{gathered}
$$

$\mathrm{d}_{\mathrm{ij}}$ and $\mathbf{k}_{\mathrm{ij}}$ 's are material constants of the composite lamina for lamina orientations of 90 and 0 degrees, respectively. The nonlinear equation of motion of the circular cylindrical laminated shell panel given by Eq. (12) is solved by using Forth Order Runge-Kutta method. 


\section{Modelling With ANSYS}

In addition to Runge-Kutta method, ANSYS finite element software is used to obtain displacement time history numerically. The finite element model for the panel consists of an assembly of $2-D$ shell elements with three layers in the transverse direction. The panel is discretized by the use of eight-noded shell elements. The discretization of the panel results in a total of 64 elements.

The pressure load as calculated earlier in the previous section is applied on the whole surface of the panel. A total of 52 time function points are used in describing the exponentially decaying blast load. All edges of the panel are modelled by fully fixed boundary conditions.

\section{RESULTS AND DISCUSSION}

Theoretical and numerical results are obtained for different radii of curvature of the three layered circular cylindrical shell, such as $25 \mathrm{~cm}, 50 \mathrm{~cm}$ and $10000 \mathrm{~cm}$ (for flat panels). All layers are taken to be of equal thicknesses. The computations are performed for the following values of parameters:

$l=22 \mathrm{~cm}, s_{0}=22 \mathrm{~cm}, h=1.2 \mathrm{~mm}, \rho=2000 \mathrm{~kg} / \mathrm{m}^{3}, v_{12}=0.23, v_{21}=0.094$

$E_{1}=60.7 \mathrm{GPa}, E_{2}=24.8 \mathrm{GPa}, P_{m}=500 \mathrm{KPa}, t_{p}=0.004 \mathrm{~s}, \alpha=1.98$.

where $E_{1}$ and $E_{2}$ are the Young's moduli and $v_{12}$ and $v_{21}$ are the Poisson ratios of the material.

The center deflection of laminated composite panel subjected to air blast loading is shown in Figs. 3 and 4. The results obtained in this analysis using linear theory are compared with the ANSYS results, in Fig. 3a. There is qualitative agreement between the linear theory and ANSYS results. Fig. $3 b$ shows the time response of the panel center obtained by the use of lineer and nonlineer geometric theory (NLG). NLG results are different from linear theory results for this loading condition. The large deflection occurs because of the large air blast load. In Fig. 4, linear theory and NLG results are presented for the circular cylindrical laminated shell panel of two different curvatures. As the curvature of panel is increased, the center deflection decreases because of increasing rigidity. The difference between linear theory and NLG results decreases because of increasing rigidity caused by curvature increase, and there is qualitative agreement between the linear and NLG cases for $r=25 \mathrm{~cm}$. (Fig. 4b). 


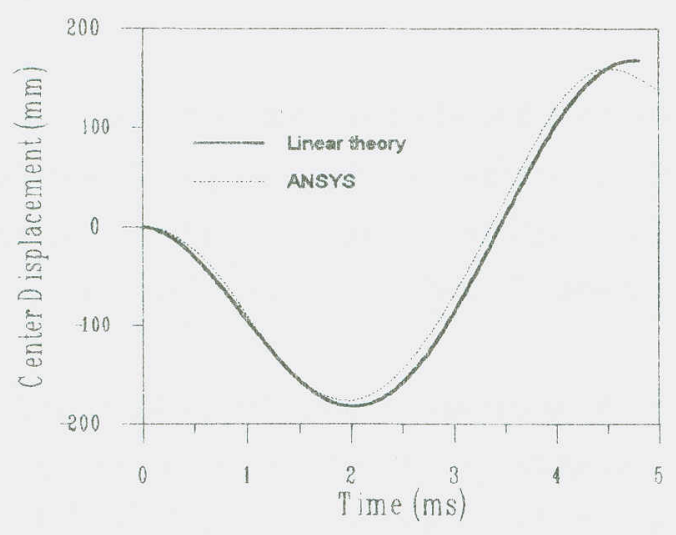

(a)

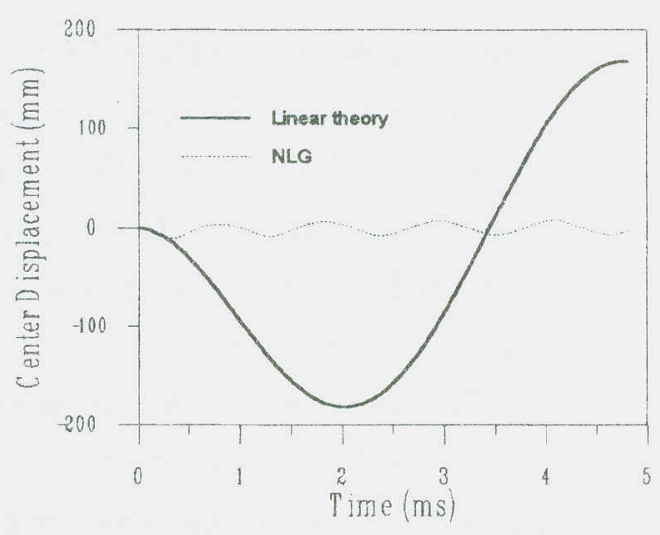

(b)

Fig. 3. Time response of flat panel to air blast loading

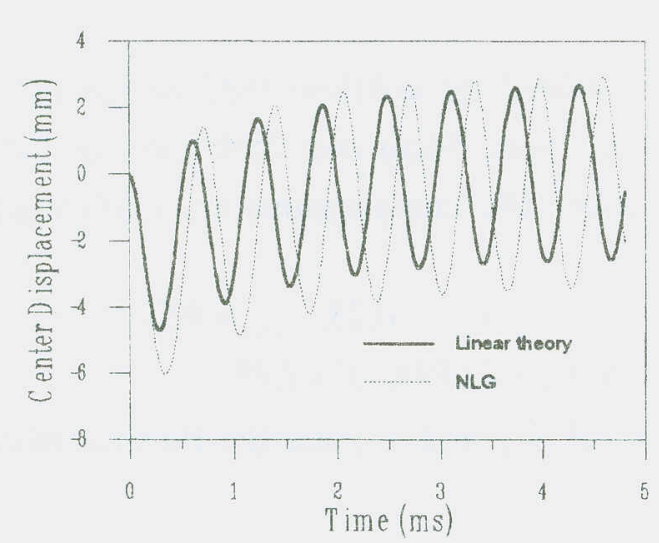

(a)

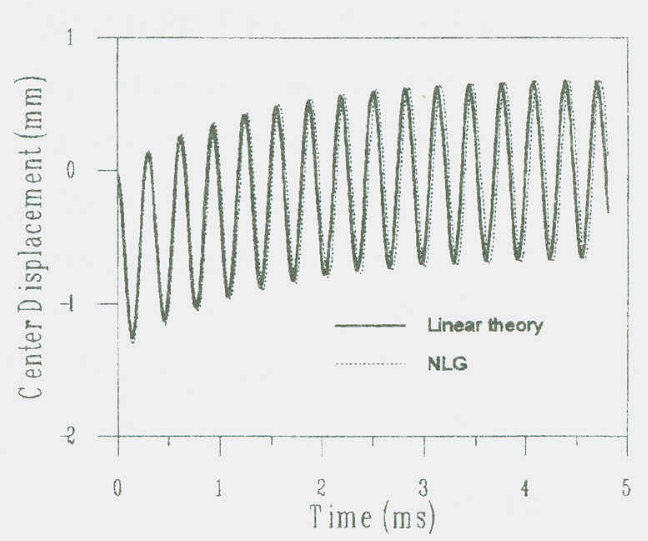

(b)

Fig. 4. Time response of panel to air blast loading (a) $r=50 \mathrm{~cm}$. (b) $r=25 \mathrm{~cm}$.

\section{CONCLUSIONS}

This paper presents a theoretical analysis and correlation with numerical results of the displacement time histories of laminated composite panels exposed to normal blast shock waves. The blast wave is assumed to be exponentially decaying with time and sinusoidally varying with coordinates. Three different radii of curvature of panel are investigated. One of them is flat panel. The equation of motion of the panel is solved using the Runge-Kutta method and correlated with ANSYS finite element results for flat panel case. The following conclusions apply to the case of laminated panels with fully fixed boundary conditions as considered herein.

The results obtained using linear theory for the flat plate are compared with the ANSYS results and a good agreement is found. Thus the theoretical solution may be used to provide material for preliminary design.

Increase in the curvature of the panel results in an increase of the vibration frequency and a decrease of the deflection, indicating a stiffening of the system. 
The effect of fiber orientation and loading conditions on the dynamic response of the laminated composite panel can be examined by this method. The hygro-thermal effects may be interesting for the aspect of the dynamic response of panel. These will be topics of further investigations.

\section{REFERENCES}

[1] B. Hopkinson, British ordnance board minutes, Report No. 13565 (1915).

[2] Houlston, R, Slater, J. E., Pegg, N. and DesRochers, C. G., "On Analysis of Structural Response of Ship Panels Subjected to Air Blast Loading", Computers and Structures, Vol. 21, No. 1/2, pp. 273-289, 1985.

[3] Houlston, R and DesRochers, C. G., "Nonlinear Structural Response of Ship Panels Subjected to Air Blast Loading", Computers and Structures, Vol. 26, No. $1 / 2, \quad$ pp. $1-15,1987$.

[4] Gupta, Aaron. D., Gregory, Frederick. H., Bitting, Robert. L. and Bhattacharya, Sujan, "Dynamic Analysis of an Explosively Loaded Hinged Rectangular Plate", Computers and Structures, Vol. 26, No. 1/2, pp. 339-344, 1987.

[5] Redekop, D. and Azar, P., "Dynamic Response of a Cylindrical Shell Panel to Explosive Loading", Joumal of Vibration and Acoustics, Vol. 113, pp. 273-278, July, 1991.

[6] Türkmen, H. S. and Mecitoğlu, Z., "Dynamic Behavior of Laminated Composite Plate Subjected to Shock Loading", First International Aerospace and Advanced Technologies Symposium, pp. 475-484, March, 1995.

[7] Librescu, L. and Nosier, A., "Response of Laminated Composite Flat Panels to Sonic Boom and Explosive Blast Loadings", AIAA Journal, Vol. 28, No. 2, pp. 345-352, February, 1990.

[8] Reddy, J. N., "Geometrically Nonlinear Transient Analysis of Laminated Composite Panels", AIAA Journal, Vol. 21, No. 4, pp. 621-629, April 1983.

[9] Beshara, F. B. A., "Modelling of Blast Loading on Aboveground Structures-I. General Phenomenology and External Blast", Computers and Structures, Vol. 51, No. 5, pp. 585-596, 1994.

[10] Mecitoğlu, Z., "Governing Equations of a Stiffened Laminated Inhomogeneous Conical Shell", AIAA Journal, Vol. 35, No. 6, June 1997(to be published).

[11] Stein, M., "Nonlinear Theory for Plates and Shells Including the Effects of Transverse Shearing", AIAA Journal, Vol. 24, No. 9, pp. 1537-1544, September 1986.

[12] Chawla, K. K., Composite Materials, Springer-Verlag, New York. 